\title{
MTHFR 677TT genotype and disease risk: is there a modulating role for B-vitamins?
}

\author{
R. Reilly, H. McNulty, K. Pentieva, J. J. Strain and M. Ward* \\ Northern Ireland Centre for Food and Health, University of Ulster, Coleraine BT52 1SA, UK
}

\begin{abstract}
Methylenetetrahydrofolate reductase (MTHFR) is a critical folate-metabolising enzyme which requires riboflavin as its co-factor. A common polymorphism $(677 \mathrm{C} \rightarrow \mathrm{T})$ in the MTHFR gene results in reduced MTHFR activity in vivo which in turn leads to impaired folate metabolism and elevated homocysteine concentrations. Homozygosity for this polymorphism (TT genotype) is associated with an increased risk of a number of conditions including heart disease and stroke, but there is considerable variability in the extent of excess risk in various reports. The present review will explore the evidence which supports a role for this polymorphism as a risk factor for a number of adverse health outcomes, and the potential modulating roles for B-vitamins in alleviating disease risk. The evidence is convincing in the case which links this polymorphism with hypertension and hypertensive disorders of pregnancy, particularly preeclampsia. Furthermore, elevated blood pressure was found to be highly responsive to riboflavin intervention specifically in individuals with the MTHFR 677TT genotype. Future intervention studies targeted at these genetically predisposed individuals are required to further investigate this novel gene-nutrient interaction. This polymorphism has also been associated with an increased risk of neural tube defects (NTD) and other adverse pregnancy outcomes; however, the evidence in this area has been inconsistent. Preliminary evidence has suggested that there may be a much greater need for women with the MTHFR 677TT genotype to adhere to the specific recommendation of commencing folic acid prior to conception for the prevention of NTD, but this requires further investigation.
\end{abstract}

\section{MTHFR 677C $\rightarrow$ T polymorphism: Folate: Riboflavin: CVD: Neural tube defects: Hypertension}

The common $677 \mathrm{C} \rightarrow \mathrm{T}$ variant in the gene that encodes the enzyme methylenetetrahydrofolate reductase (MTHFR) is widely recognised as the most important genetic determinant of elevated homocysteine concentration in healthy populations. Emerging evidence links the MTHFR $677 \mathrm{C} \rightarrow \mathrm{T}$ polymorphism with a greater risk of $\mathrm{CHD}^{(1)}$, stroke ${ }^{(2)}$ and more recently hyperten$\operatorname{sion}^{(3)}$, although there is considerable variability in the extent of excess disease risk in different populations, an observation that is generally explained by differences in folate status. The potential roles of folate and the related $\mathrm{B}$-vitamins in the risk of these and other common diseases have been widely investigated over the past two decades, but relatively few studies have specifically investigated the roles of the relevant gene-nutrient interactions in modulating the risk of disease.
The role of maternal folate status in early pregnancy for the prevention of neural tube defects (NTD) is well established $^{(4,5)}$. In addition, other pregnancy complications such as gestational hypertension and preeclampsia have been associated with low maternal folate status $^{(6,7)}$. Although the mechanisms linking low folate status to these pregnancy complications are not fully understood, the identification of genes that may predispose women to adverse pregnancy events has been the focus of much research. There is now strong evidence to support a role for the MTHFR $677 \mathrm{C} \rightarrow \mathrm{T}$ polymorphism in adverse pregnancy outcomes ${ }^{(8,9)}$. The present paper will explore the evidence linking this polymorphism with various disease states and the potential modulating role for B-vitamins in alleviating any excess disease risk. 
Table 1. Meta-analyses that investigated the MTHFR $677 \mathrm{C} \rightarrow$ T polymorphism and CVD risk by geographical region

\begin{tabular}{|c|c|c|c|}
\hline Author & $\begin{array}{l}\text { Sample } \\
\text { size }(n)\end{array}$ & Region & $\begin{array}{l}\text { Odds ratio } \\
(95 \% \mathrm{Cl})\end{array}$ \\
\hline Klerk et al. ${ }^{(1)}$ & 23920 & $\begin{array}{l}\text { All } \\
\text { Europe } \\
\text { North America }\end{array}$ & $\begin{array}{l}1.16(1.05,1.28) \\
1.14(1.01,1.28) \\
0.87(0.73,1.05)\end{array}$ \\
\hline $\begin{array}{l}\text { Wald et al. }{ }^{(21)} \\
\text { Casas et al. }{ }^{(22)}\end{array}$ & $\begin{array}{l}16849 \\
13928\end{array}$ & $\begin{array}{l}\text { All } \\
\text { All } \\
\text { North America/Europe }\end{array}$ & $\begin{array}{l}1.42(1.11,1.84) \\
1.26(1.14,1.40) \\
1.21(1.02,1.43)\end{array}$ \\
\hline Lewis et al. ${ }^{(20)}$ & 57183 & $\begin{array}{l}\text { All } \\
\text { Middle East } \\
\text { Asia } \\
\text { Europe } \\
\text { North America } \\
\text { Australia }\end{array}$ & $\begin{array}{l}1.14(1.05,1.24) \\
2.61(1.81,3.75) \\
1.23(0.94,1.62) \\
1.08(0.99,1.18) \\
0.93(0.80,1.10) \\
1.04(0.73,1.49)\end{array}$ \\
\hline Holmes et al. ${ }^{(2)}$ & 45549 & $\begin{array}{l}\text { All } \\
\text { Asia } \\
\text { North America, Australia } \\
\text { and New Zealand }\end{array}$ & $\begin{array}{l}1.37(1.25,1.50) \\
1.68(1.44,1.97) \\
1.03(0.84,1.25)\end{array}$ \\
\hline Clarke et al. ${ }^{(24)}$ & 70474 & $\begin{array}{l}\text { All } \\
\text { Asia } \\
\text { Europe } \\
\text { USA and Australasia }\end{array}$ & $\begin{array}{l}1.15(1.09,1.21) \\
1.49(1.29,1.73) \\
1.11(0.93,1.22)^{\star} \\
1.04(0.79,1.36)^{\star}\end{array}$ \\
\hline
\end{tabular}

${ }^{*}$ Reported after national folate supplementation in the USA, Canada, Australia, New Zealand and some but not all European countries.

\section{MTHFR 677TT genotype in $\mathrm{C}_{1}$ metabolism}

The MTHFR enzyme requires the B-vitamin riboflavin in its co-enzymatic form flavin adenine dinucleotide to catalyse the conversion of 5,10-methylenetetrahydrofolate to 5-methyltetrahydrofolate. This enzyme plays a key role in regulating the availability of methyl groups required for the remethylation of homocysteine into methionine. The common $677 \mathrm{C} \rightarrow \mathrm{T}$ variant results in a less active thermolabile MTHFR enzyme typically leading to elevated homocysteine concentration in vivo ${ }^{(10)}$. In vitro evidence indicates that the reduced activity of the variant enzyme is the result of an increased propensity to dissociate from its FAD co-factor ${ }^{(11,12)}$. The finding of lower erythrocyte folate concentrations in individuals with the homozygous mutant TT genotype compared with those without this genetic variant, has led to the suggestion that folate requirements may be increased in these individuals ${ }^{(13)}$. Furthermore, homocysteine concentrations are found to be highest under conditions of suboptimal folate status in combination with the TT genotype ${ }^{(14,15)}$.

The B-vitamins folate and riboflavin (along with the metabolically related B-vitamins, $\mathrm{B}_{12}$ and $\mathrm{B}_{6}$ ) are important nutritional determinants of homocysteine concentrations. Supplementation with folic acid, the synthetic form of folate, has been shown to lower elevated homocysteine concentrations by approximately $25 \%$ in the population generally ${ }^{(16)}$. In the case of riboflavin, however, the homocysteine-lowering effects are confined to those with the MTHFR 677TT genotype. Riboflavin supplementation specifically in individuals with the TT genotype has been shown to significantly lower plasma homocysteine by $22 \%$, and by as much as $40 \%$ in those with the lowest riboflavin status at baseline ${ }^{(17)}$. This response was not observed in individuals with $\mathrm{CC}$ or CT genotypes (even when baseline riboflavin status was suboptimal) despite a significant improvement in riboflavin status post-intervention in both genotype groups. Such evidence confirmed the independent modulating role of riboflavin in determining homocysteine concentrations specifically in individuals with the TT genotype as first suggested by earlier observational studies ${ }^{(18,19)}$.

\section{Association between the MTHFR $677 \mathrm{C} \rightarrow \mathrm{T}$ polymorphism and CVD risk}

The MTHFR $677 \mathrm{C} \rightarrow \mathrm{T}$ polymorphism previously received much attention as the main genetic determinant of homocysteine ${ }^{(10)}$ and is also independently associated with an increased risk of CVD and particularly stroke $^{(1,2,20,21)}$. Several meta-analyses to date have demonstrated an increased risk of CVD in individuals with the TT genotype compared to those without this genetic variant ${ }^{(1,2,20-22)}$ (Table 1). Those studies which assessed the risk of CHD events estimated a $14-16 \%$ higher risk in individuals with the TT genotype compared to those with the CC genotype ${ }^{(20,23)}$. The most recent meta-analysis considered published and unpublished results in the area and estimated that the MTHFR 677TT genotype carried a $15 \%$ excess risk of heart disease (based on published results) ${ }^{(24)}$. 
Differences in B-vitamin status may in some way explain the large geographical variation in the extent of the excess risk, which has previously been reported in relation to this polymorphism (Table 1). Klerk et al. ${ }^{(1)}$ and Lewis et al. ${ }^{(20)}$ found no strong evidence to support an association between the TT genotype and risk of CHD among North American populations; however, the polymorphism was linked to an increased risk of CHD among Asian and Middle Eastern populations. It was concluded that such geographical differences reflected the influence of environmental factors (primarily folate status) on the interaction between the polymorphism and CVD risk ${ }^{(2,25)}$. In terms of stroke, the TT genotype was associated with an increased risk in regions of low folate only; whereas in populations of optimal folate status or in regions of mandatory folic acid fortification, the effect of the TT genotype on stroke risk was null ${ }^{(2)}$. Somewhat surprisingly however, recent prospective evidence from the National Health and Nutrition Examination Survey cohort reported that the MTHFR 677TT genotype was associated with a lower rate of CVD mortality (OR 0.69 (95\% CI $0.50,0.95)$ ), although stratified analysis found that this association only occurred after the introduction of mandatory folic acid fortification ${ }^{(26)}$.

Overall, the evidence supports a modulating role of folate on CVD risk in this genetically at-risk group. However caution is required when interpreting the results from some observational studies. Further large-scale genetic studies, particularly among populations with suboptimal folate status, are required to fully investigate the extent of CVD risk associated with this polymorphism and to consider the role of metabolically related B-vitamins linked with folate.

\section{MTHFR $677 \mathrm{C} \rightarrow$ T polymorphism and blood pressure}

Hypertension, defined as a blood pressure (BP) of $140 / 90 \mathrm{mmHg}$ or greater, is a major risk factor for CVD, with uncontrolled hypertension associated with an almost threefold greater risk of developing $\mathrm{CVD}^{(27)}$. Furthermore, elevated BP is recognised as an even stronger predictor of stroke. A modest lowering of systolic BP by $2-\mathrm{mmHg}$ is estimated to decrease cardiovascular risk by $10 \%$, whereas a lowering of $10-\mathrm{mmHg}$ is associated with a $40 \%$ reduction in stroke mortality ${ }^{(28)}$.

Approximately $30-60 \%$ of BP variability is considered to be inherited ${ }^{(29,30)}$ and several studies have focused on investigating genetic variants associated with elevated BP. Recent genome-wide association studies have investigated associations between single-nucleotide polymorphisms and elevated $\mathrm{BP}^{(3,31)}$. One such study, which included data from 34433 individuals, reported that the MTHFR loci was one of eight loci related to $\mathrm{BP}$; however, the authors noted that there may be other genetic variants linked to the BP located in this region which have not been considered or are still unknown ${ }^{(3)}$. Several subsequent investigations of a genome-wide association studies nature have confirmed the association between the MTHFR gene and BP variability $^{(32-34)}$.

The evidence from case-control studies suggests that there is a graded association between the MTHFR $677 \mathrm{~T}$ allele and BP risk among hypertensive populations across different ethnic groups. An early case-control study in a Caucasian-Australian population reported a significantly higher frequency of the TT genotype in cases with hypertension compared to controls (after adjustment for BMI) ${ }^{(35)}$. Within an Asian-Indian population, a nearly fourfold increased risk of hypertension in individuals with the TT genotype was reported ${ }^{(36)}$. Interestingly, in a large population-based study of over 3000 Japanese people, the TT genotype was associated with a $42 \%$ increased risk of hypertension in women; however no significant association was shown in men ${ }^{(37)}$. As the evidence accumulated to support an association between the MTHFR $677 \mathrm{C} \rightarrow \mathrm{T}$ polymorphism and hypertension risk, a number of meta-analyses were carried out. One meta-analysis of thirteen casecontrol studies ${ }^{(38)}$ confirmed a significant association between the TT genotype and hypertension among the Asian and the Caucasian populations, albeit significant heterogeneity was reported (OR 1.24 (95\% CI 1.02 , 1.50)). The most recent meta-analysis, which attempted to address the issue of heterogeneity by focusing specifically on Chinese population studies only, reported a $87 \%$ increased risk of hypertension in individuals with the TT genotype compared to those with the CC genotype ${ }^{(8)}$. Similarly, case-control studies carried out in hypertensive patients with various co-morbidities such as diabetes ${ }^{(39)}$, coronary artery disease ${ }^{(40)}$ and chronic renal failure ${ }^{(4 \hat{1})}$ have also reported significant associations between this polymorphism and hypertension.

In addition to lifestyle and dietary modifications, improvements in the management of BP are largely considered to be due to the development of effective antihypertensive medications. Such medications are broadly categorised into five main classes (diuretics, $\beta$-blockers, calcium channel blockers, angiotension converting enzyme inhibitors and angiotension II receptor blockers), all of which have slightly different mechanisms of action. Only a limited number of studies, however, have investigated whether the BP-lowering effect of antihypertensive medications is influenced by the MTHFR $677 \mathrm{C} \rightarrow \mathrm{T}$ polymorphism. Jiang et al. ${ }^{(42)}$ reported an increased diastolic BP response to treatment with an angiotension converting enzyme inhibitor in hypertensive patients with the TT genotype compared to those without the polymorphism. More recently, in a larger cohort of hypertensive patients with the TT genotype (who expressed the phenotype of elevated BP at baseline), an increased diastolic $\mathrm{BP}$ response to treatment with an angiotension converting enzyme inhibitor was again reported $(P=0.038)^{(43)}$. Similarly, short-term treatment with a calcium channel blocker resulted in a significantly higher pulse wave velocity response in patients with the TT genotype compared with those with $\mathrm{CC}$ and $\mathrm{CT}$ genotypes $(P=0.018)$; the polymorphism however did not affect the antihypertensive effects of the calcium channel blocker treatment $^{(44)}$. In contrast, other studies (reviewed later) 
suggest that the response to antihypertensive medication is generally suboptimal in individuals with the TT genotype compared to those with the CC or CT genotype. Given the limited evidence to date, further work is needed to explore potential interactions between the $M T H F R$ 677C $\rightarrow \mathrm{T}$ polymorphism and the antihypertensive effects of various BP medications.

\section{MTHFR genotype and the modulating potential of B-vitamins in blood pressure control}

Although strong evidence shows an association between the $M T H F R$ $677 \mathrm{C} \rightarrow \mathrm{T}$ polymorphism and hypertension, the interrelationships between MTHFR genotypes, B-vitamin status and hypertension risk are not generally appreciated. In one small placebo-controlled, cross-over design study ( $n$ 41), Williams et $a l .^{(45)}$ reported a decreased pulse pressure and arterial stiffness following short-term folic acid supplementation $(5 \mathrm{mg} / \mathrm{d})$; an effect that was reported to be independent of homocysteine concentration or $M T H F R$ genotype, but the lack of statistical power (i.e. only five subjects with the TT genotype were available for investigation) makes such conclusions questionable. A subsequent intervention study reported no BP response to short-term folic acid supplementation, but did observe an association between $M T H F R$ T allele frequency and hypertension risk ${ }^{(46)}$. Owing to the opportunistic nature of such studies (and therefore the lack of genotype-driven recruitment) such inconsistent results are not surprising. Similarly, in the large-scale trials of CVD risk involving folic acid intervention with or without other B-vitamins, no response of BP has been reported to date; however, no trial has analysed the results of $\mathrm{BP}$ (or other CVD outcomes) by $M T H F R$ genotype $^{(47,48)}$.

Given the emerging evidence linking hypertension with this polymorphism ${ }^{(3)}$ and the established genotypespecific response of homocysteine to riboflavin supplementation $^{(17)}$, recent research from our Centre has focused on investigating the BP-lowering potential of riboflavin in hypertensive individuals with the TT genotype. In a placebo-controlled trial, premature CVD patients (pre-screened for the $M T H F R$ 677C $\rightarrow \mathrm{T}$ polymorphism) were randomised within all three genotype groups to receive either riboflavin $(1.6 \mathrm{mg} / \mathrm{d})$ or placebo over a 16-week intervention period. Baseline BP was significantly higher in patients with the TT genotype compared to those with other genotypes; an effect that was most pronounced in those with the lowest baseline riboflavin status (as determined by the biomarker erythrocyte glutathione reductase activation co-efficient). Systolic and diastolic BP decreased significantly (by 13 and $8 \mathrm{mmHg}$, respectively) in those individuals with the TT genotype but no response was observed in the other genotype groups ${ }^{(49)}$. A follow-up, cross-over, randomised controlled trial reinvestigated the effect of riboflavin on BP in the same cohort of high-risk CVD patients 4 years after the original investigation ${ }^{(50)}$. Although there were marked changes in prescribed antihypertensive therapy over the 4-year period, the mean BP of those with the TT genotype (who originally received riboflavin supplementation for the 16-week period) had returned to pre-intervention levels. When the original treatment groups were reversed, the genotype-specific BP-lowering effect of riboflavin was again confirmed ${ }^{(50)}$ with reductions of $9.2(\mathrm{SD} 12.8) \mathrm{mmHg}(P=0.001)$ and 6.0 (SD 9.9) $\mathrm{mmHg}(P=0.003)$ in systolic and diastolic BP, respectively. Most recently, the responsiveness of $\mathrm{BP}$ to riboflavin supplementation in a separate cohort of treated hypertensive individuals (without overt CVD) with the TT genotype ( $n$ 91) was investigated ${ }^{(51)}$. At baseline, $60 \%$ of the participants had failed to achieve target BP levels $(\leq 140 / 90 \mathrm{mmHg})$, despite taking three or more antihypertensive medications. Following riboflavin intervention $(1.6 \mathrm{mg} / \mathrm{d}$ for 16 weeks), systolic BP decreased significantly, a finding which confirmed that the BP-lowering effects of riboflavin in individuals with the MTHFR 677TT genotype were not confined to high-risk CVD patients but also applied to hypertensive individuals generally ${ }^{(51)}$.

Although accumulating evidence highlights the BP-lowering effects of riboflavin in hypertensive individuals with the $M T H F R \quad 677 \mathrm{C} \rightarrow \mathrm{T}$ polymorphism, the mechanism to explain the role of this gene-nutrient interaction in BP remains unclear. It is possible however that the potent vasodilator nitric oxide may be involved. Decreased vascular concentrations of 5-methlytetrahydrolfolate, a nitric oxide regulator, have been reported in those with the MTHFR 677TT genotype ${ }^{(52)}$. By stabilising the variant enzyme via riboflavin supplementation, it is possible that normal concentrations of 5-methyltetrahydrofolate would be restored in vascular cells, thus improving the bioavailability of nitric oxide and resulting in BP-lowering specifically in those with the TT genotype. Further investigations are required to explore this and other potential mechanisms as well as the role of other B-vitamins involved in $\mathrm{C}_{1}$ metabolism. Given the known metabolic interdependencies between the relevant B-vitamins, work is underway at this Centre to investigate the independent and combined effects of riboflavin and folic acid on BP in hypertensive individuals with the TT genotype in a factorial study design. In addition, although convincing evidence has demonstrated the BP-lowering effects of low-dose riboflavin over a relatively short period of time $(1.6 \mathrm{mg} / 16 \text { weeks })^{(49-51)}$, it remains to be seen how variations in dose and duration would influence the BP-lowering effects of riboflavin in these genetically at-risk patients.

\section{MTHFR genotype, B-vitamins and pregnancy outcomes}

Well-established evidence has accumulated to suggest a link between the $M T H F R \quad 677 \mathrm{C} \rightarrow \mathrm{T}$ polymorphism and the risk of certain adverse pregnancy outcomes including NTD as well as hypertensive disorders such as preeclampsia and gestational hypertension; some of which will be the focus of the next section of this review. 


\section{The link between the B-vitamins and neural tube defects}

NTD are of multi-factorial origin and involve both genetic and environmental factors. Landmark studies in the early 1990s confirmed the protective effects of periconceptional folic acid supplementation against the first occurrence $^{(4)}$ and reoccurrence ${ }^{(5)}$ of NTD. Of note, Daly et al. ${ }^{(53)}$ illustrated a dose-response inverse relationship between maternal red cell folate (RCF) and NTD risk and identified maternal $\mathrm{RCF}$ concentrations of $\geq 906 \mathrm{nmol} / 1$ as the level associated with the lowest risk of an NTD affected pregnancy. Subsequently, folic acid supplementation levels of 400,200 or $100 \mu \mathrm{g} / \mathrm{d}$ were reported to produce RCF concentrations, which predicted reductions in NTD by 47,41 and $22 \%$, respectively ${ }^{(54)}$

Present recommendations, in place in most countries worldwide, are that women planning a pregnancy should take a folic acid supplement of $400 \mu \mathrm{g} / \mathrm{d}$ for at least 1 month before conception and during the first trimester of pregnancy ${ }^{(55)}$. Reports have confirmed, however, that the uptake of this recommendation among women of child bearing age is typically poor ${ }^{(56,57)}$ and so it is not surprising that the NTD rates have changed very little across several European countries as a result of these folic acid recommendations ${ }^{(58)}$. In contrast, the introduction of mandatory fortification of food with folic acid in the USA has successfully increased both serum and RCF concentrations among women of childbearing age ${ }^{(59)}$ which has coincided with a $27-50 \%$ reduction in the reported prevalence of NTD in the USA and Canada ${ }^{(60,61)}$. At a global level, folic acid fortification of food in countries worldwide has led to an estimated $46 \%$ reduction in the prevalence of NTD since $2008^{(62)}$.

\section{The role of the MTHFR $677 \mathrm{C} \rightarrow \mathrm{T}$ polymorphism in neural tube defects}

To date, no single gene or genetic variant has been identified as a risk factor for NTD. Given the established protective effects however, of folic acid supplementation on the occurrence and reoccurrence of NTD, polymorphisms in genes encoding the proteins that are directly involved in folate metabolism, uptake and transport have been investigated. The reduced activity of the MTHFR enzyme in individuals with the MTHFR 677TT genotype, decreases the availability of 5-methyltetrahydrofolate which plays a key role in methylation $^{(10)}$ and decreases global DNA methylation $^{(63,64)}$; therefore, it is no surprise that this specific mutant gene has been extensively investigated as a genetic risk factor for $\mathrm{NTD}^{(65,66)}$.

Over the past two decades, several reports have shown a 2 to 4 -fold increased risk of NTD if the infant or the mother has the MTHFR 677TT genotype ${ }^{(65,67-70)}$. van der Put et al. ${ }^{(71)}$ reported an even higher risk of an NTD pregnancy if both the mother and the fetus were homozygous for the MTHFR $677 \mathrm{C} \rightarrow \mathrm{T}$ polymorphism. The large meta-analysis conducted by Botto and Yang $^{(9)}$ considered the frequency of the MTHFR
$677 \mathrm{C} \rightarrow \mathrm{T}$ polymorphism and the risk of NTD across a number of different countries and ethnic groups. Overall, a 1.8 to 2 -fold increased risk of spina bifida was established regardless of whether the infant or the mother was homozygous for the MTHFR $677 \mathrm{C} \rightarrow \mathrm{T}$ polymorphism ${ }^{(9)}$. However, other reports have indicated that the presence of the MTHFR 677TT genotype in the infant, and not in the mother, was the relevant consideration in NTD risk ${ }^{(72)}$. Although Shaw et al. ${ }^{(73)}$ established an association between the TT genotype and spina bifida risk, only a weak interaction between the infant genotype and maternal folic acid usage in the occurrence of spina bifida was reported, possibly suggesting that other contributing factors may also need to be considered. Studies focusing on maternal rather than infant MTHFR genotype have found that maternal folate status and/or maternal homozygosity for the MTHFR $677 \mathrm{C} \rightarrow \mathrm{T}$ genotype are important determinants of NTD risk ${ }^{(74,75)}$. Evidence from the aforementioned meta-analysis suggested that the excess NTD risk associated with the TT genotype may depend on folate status and/or a variant of other folate-related genes ${ }^{(9)}$. Christensen et al. ${ }^{(76)}$ demonstrated a 13 -fold increased risk for spina bifida where the TT genotype was combined with RCF concentrations within the lowest quartile, a finding that strongly supports a genenutrient interactive effect being implicated in NTD risk, and also may explain some of the inconsistencies within the literature in this area.

Limited studies have investigated the influence of the $M T H F R$ TT genotype in relation to present folic acid recommendations for the prevention of NTD. Preliminary evidence from a study conducted by our group reported that among women with the TT genotype, sampled at the fourteenth gestational week, significantly increased homocysteine and lower RCF concentrations were observed if folic acid supplementation $(400 \mu \mathrm{g} / \mathrm{d})$ was commenced prior to conception (i.e as recommended) compared with post-conception (i.e. more typical practice); such differences were not evident in the other genotype groups ${ }^{(77)}$. Furthermore, a large randomised controlled trial reported that despite 6 months supplementation with $4000 \mu \mathrm{g} / \mathrm{d}$ folic acid, women of childbearing age with the TT genotype achieved lower serum folate concentrations than did those with the CC genotype $^{(78)}$. Such evidence strongly suggests that folate requirements are higher in women with the MTHFR TT genotype and highlights the much greater need for women with this genotype to adhere to the specific recommendation of commencing folic acid prior to conception in order to optimise folate status for the prevention of NTD, although these findings need to be confirmed in larger studies among different populations.

\section{Role of the MTHFR genotype in determining the risk of hypertensive disorders of pregnancy}

Hypertensive disorders of pregnancy, such as gestational hypertension and preeclampsia affect 5-7\% of all low-risk pregnancies worldwide and are the 
Table 2. Studies that investigated the association between the MTHFR $677 \mathrm{C} \rightarrow$ T polymorphism and preeclampsia risk

\begin{tabular}{|c|c|c|c|}
\hline Author & Sample size & Country/population & Odds ratio $(95 \% \mathrm{Cl})$ \\
\hline Sohda et al. ${ }^{(87)}$ & 425 & Japan & $2.5(1.3,4.8)$ \\
\hline Grandone et al. ${ }^{(88)}$ & 225 & Italy & $1.8(1.0,3.5)$ \\
\hline Kupferminc ${ }^{(96)}$ & 144 & Israel & $2.9(1.0,8.5)$ \\
\hline Powers et al. ${ }^{(97)}$ & 237 & Caucasian women & $1.28(0.58,2.79)$ \\
\hline Kobashi et al. ${ }^{(98)}$ & 316 & Japan & $0.68(0.30,1.55)$ \\
\hline Laivuori et al. ${ }^{(99)}$ & 216 & Finland & $0.50(0.14,1.77)$ \\
\hline Rigo et al. ${ }^{(100)}$ & 221 & Caucasian women & $1.13(0.38,3.37)$ \\
\hline Morrison et al. ${ }^{(101)}$ & 404 & Scotland & $1.00(0.55,1.82)$ \\
\hline Prasmusinto et al. ${ }^{(102)}$ & 112 & Germany and Croatia & $0.28(0.03,2.47)$ \\
\hline Pegoraro et al. ${ }^{(103)}$ & 609 & South African (Black) & $0.62(0.06,6.90)$ \\
\hline Perez-Mutul et al. ${ }^{(91)}$ & 325 & Mexico & $0.94(0.59,1.49)$ \\
\hline Williams et al. ${ }^{(104)}$ & 304 & Peru & $1.6(0.7,3.8)$ \\
\hline Yilmaz et al. ${ }^{(105)}$ & 111 & Turkey & $0.84(0.26,2.67)$ \\
\hline Also-Rallo et al. ${ }^{(79)}$ & 165 & Spain & $0.73(0.31,1.76)$ \\
\hline Hernandez-Diaz et al. ${ }^{(86)}$ & 154 & USA/Canada & $3.0(1 \cdot 2,7 \cdot 7)$ \\
\hline Stiefel et al. ${ }^{(106)}$ & 584 & Spain & $0.92(0.50,1.71)$ \\
\hline
\end{tabular}

leading cause of maternal and fetal morbidity and mortality ${ }^{(79)}$. Gestational hypertension occurs without proteinuria (a predominant feature of preeclampsia), but increases the risk of developing preeclampsia by $15-26 \%{ }^{(80)}$. Historical investigations reported an association between gestational hypertension and folate deficiency ${ }^{(81-84)}$.

In the past two decades, a plethora of studies has investigated the effect of B-vitamin supplementation on hypertensive disorders of pregnancy. The evidence, however, remains inconsistent. Bodnar et al. ${ }^{(6)}$ and Hernandez et al. ${ }^{(7)}$ reported that regular users of a multivitamin containing folic acid compared with non-users, had a reduced risk of developing preeclampsia and gestational hypertension by 45 and $55 \%$, respectively. However, Ray and Mamdani ${ }^{(85)}$ compared the rate of preeclampsia before and after population-wide fortification of food with folic acid in Canada and reported only a small reduction in the rate of preeclampsia (OR $0.96(95 \%$ CI $0.94,0.98))$. It is possible that such inconsistencies may be explained to some extent by different frequencies of the MTHFR $677 \mathrm{C} \rightarrow \mathrm{T}$ genotype among study populations.

Hernandez-Diaz et al. ${ }^{(86)}$ found a significant association between the MTHFR 677TT genotype and risk of gestational hypertension and noted that this association may be weakened among women taking folic acid supplementation. Convincing evidence from metaanalyses has also reported a link between this polymorphism and the risk of hypertensive disorders of pregnancy. Qian et al. $^{(38)}$ conducted a meta-analysis among Caucasian and Asian populations and reported a 1.66-fold increased risk of hypertension-in-pregnancy in $\mathrm{T}$ allele carriers; however, significant heterogeneity was noted. Subgroup analysis found that the $T$ allele was associated with an increased risk of hypertension in Asians only, whereas no significant association was found in Caucasians. In general agreement with these findings, a subsequent meta-analysis that included studies in Chinese populations only, reported a significant association between the MTHFR $677 \mathrm{C} \rightarrow \mathrm{T}$ polymorphism and risk of hypertension-in-pregnancy ${ }^{(8)}$.

Apart from gestational hypertension, the closely related hypertensive-disorder of pregnancy, preeclampsia, has separately been investigated in relation to the MTHFR $677 \mathrm{C} \rightarrow$ T polymorphism. In 1997, two separate case-control studies independently reported a significant association between the TT genotype and preeclampsia $^{(87,88)}$. Since then, numerous studies have investigated this association; however, conflicting results have emerged (Table 2). Worldwide, Mexico has the highest frequency of the TT genotype ${ }^{(89)}$ as well as a high prevalence of preeclampsia ${ }^{(90)}$. Within populations from two regions of Mexico, however, Perez-Mutul et al. ${ }^{(91)}$ and Davalos et al. ${ }^{(92)}$ reported no significant association between the polymorphism and preeclampsia in pregnant women. In contrast, Canto et al. ${ }^{(93)}$ reported from another group of pregnant Mexican women, that the TT genotype (compared to the CC and CT genotypes) was associated with a decreased risk of preeclampsia, following adjustment for age and BMI. Such discrepancies between studies may suggest that the effect of the MTHFR 677TT genotype may be modulated by relevant dietary and environmental factors that could vary considerably among different populations.

The association between the MTHFR $677 \mathrm{C} \rightarrow \mathrm{T}$ polymorphism and preeclampsia has been addressed in several meta-analyses. Kosmas et al. ${ }^{(94)}$ reported that the TT genotype compared with the CC genotype was associated with a $33 \%$ increased risk of preeclampsia, however significant between-study heterogeneity was found. Most recently, the meta-analysis by Xia et al. ${ }^{(95)}$ reported that the TT genotype compared with the CC and CT genotypes carried a significantly greater risk of preeclampsia (by $76 \%$ ) among Asian women only, whereas in Caucasian women this increased risk was not evident. It is worth noting however that a much greater number of large-scale studies in this area have been conducted within Asian populations with far fewer studies conducted in Caucasian populations; a factor that limits 
the extent to which different populations can be compared. An additional limitation is that genotype-driven recruitment is generally not undertaken in these studies, a feature that is reflected by the relatively small numbers of pregnant women with the TT genotype being investigated and these raised the concern that many such studies may be statistically underpowered. It is not surprising therefore that in some cases the association between the MTHFR polymorphism and gestational hypertension is found to be relatively weak. In addition, the modulating effects of the polymorphism in relation to hypertension may be masked by the presence of other risk factors, such as reduced physical activity, increased BMI and gestational diabetes, which can develop during pregnancy and increase BP.

\section{Conclusion}

Overall, convincing evidence supports an independent role for the MTHFR $677 \mathrm{C} \rightarrow \mathrm{T}$ polymorphism as a risk factor for a number of adverse health outcomes, but there are considerable inconsistencies among individual studies. The MTHFR 677TT genotype has been shown in several populations to be an important determinant of hypertension and this may provide a possible explanation for the excess risk of CVD generally linked with this polymorphism as reported in numerous meta-analyses. In addition to the widely acknowledged modulating role of folate, riboflavin (which has been largely overlooked to date) is emerging as an important nutrient that drives the phenotype and potentially the disease risk associated with the MTHFR $677 \mathrm{C} \rightarrow \mathrm{T}$ polymorphism. Given the genotype-specific responsiveness of $\mathrm{BP}$ to riboflavin intervention demonstrated in trials from this Centre, it is possible that the large geographical variations in the extent of disease risk may relate not only to comprised folate status, as commonly suggested, but may also be the result of differences in prevailing riboflavin status among different populations. Large genotypedriven intervention trials (involving pre-screening to select individuals with the TT genotype) conducted within unfortified regions or among populations with sub-optimal B-vitamin status are required to confirm this. Overall, there is convincing evidence of the potential for a personalised approach to disease prevention or treatment, whereby B-vitamin intervention may be targeted at those individuals sharing this common genetic factor.

\section{Acknowledgements}

None.

\section{Financial Support}

This work was supported by funding from the Northern Ireland Department for Employment and Learning which funded the $\mathrm{PhD}$ studentship for R. R. The
Northern Ireland Department for Employment and Learning had no role in the design, analysis or writing of this article.

\section{Conflicts of Interest}

There is a patent granted in Europe and pending elsewhere by H. McN., J. J. S. and M. W. on the use of riboflavin in the treatment of hypertension.

\section{Authorship}

R. R. drafted the manuscript. M. W., H. McN., K. P. and J. J. S. critically revised the manuscript for important intellectual content. All the authors have read and approved the final manuscript.

\section{References}

1. Klerk M, Verhoef P, Clarke R et al. (2002) MTHFR $677 \mathrm{C} \rightarrow \mathrm{T}$ polymorphism and risk of coronary heart disease - a meta-analysis. JAMA 288, 2023-2031.

2. Holmes MV, Newcombe P, Hubacek JA et al. (2011) Effect modification by population dietary folate on the association between MTHFR genotype, homocysteine, and stroke risk: a meta-analysis of genetic studies and randomised trials. Lancet 378, 584-594.

3. Newton-Cheh C, Johnson T, Gateva $\mathrm{V}$ et al. (2009) Genome-wide association study identifies eight loci associated with blood pressure. Nat Genet 41, 666676.

4. Czeizel A \& Dudas I (1992) Prevention of the 1st occurrence of neural-tube defects by periconceptional vitamin supplementation. $N$ Engl J Med 327, 1832-1835.

5. MRC Vitamin Study Research Group (1991) Prevention of neural tube defects: results of the Medical Research Council Vitamin Study. Lancet 338, 131-137.

6. Bodnar LM, Tang G, Ness RB et al. (2006) Periconceptional multivitamin use reduces the risk of preeclampsia. Am J Epidemiol 164, 470-477.

7. Hernandez-Diaz S, Werler MM, Louik C et al. (2002) Risk of gestational hypertension in relation to folic acid supplementation during pregnancy. Am J Epidemiol 156, 806-812.

8. Niu WQ, You YG \& Qi Y (2012) Strong association of methylenetetrahydrofolate reductase gene C677T polymorphism with hypertension and hypertension-inpregnancy in Chinese: a meta-analysis. $J$ Hum Hypertens 26, 259-267.

9. Botto LD \& Yang QH (2000) 5,10-Methylenetetrahydrofolate reductase gene variants and congenital anomalies: a HuGE review. Am J Epidemiol 151, 862877.

10. Frosst P, Blom HJ, Milos R et al. (1995) A candidate genetic risk factor for vascular disease: a common mutation in methylenetetrahydrofolate reductase. Nat Genet 10, 111-113.

11. Guenther BD, Sheppard CA, Tran P et al. (1999) The structure and properties of methylenetetrahydrofolate reductase from Escherichia coli suggest how folate ameliorates human hyperhomocysteinemia. Nat Struct Biol 6, $359-365$. 
12. Yamada K, Chen Z, Rozen R et al. (2001) Effects of common polymorphisms on the properties of recombinant human methylenetetrahydrofolate reductase. Proc Natl Acad Sci USA 98, 14853-14858.

13. Molloy AM, Daly S, Mills JL et al. (1997) Thermolabile variant of 5,10-methylenetetrahydrofolate reductase associated with low red-cell folates: implications for folate intake recommendations. Lancet 349, 1591-1593.

14. Jacques PF, Bostom AG, Williams RR et al. (1996) Relation between folate status, a common mutation in methylenetetrahydrofolate reductase, and plasma homocysteine concentrations. Circulation 93, 7-9.

15. Brattstrom L, Wilcken DEL, Ohrvik J et al. (1998) Common methylenetetrahydrofolate reductase gene mutation leads to hyperhomocysteinemia but not to vascular disease - the result of a meta-analysis. Circulation 98, 2520-2526.

16. Homocysteine Lowering Trialists' Collaboration (2005) Dose-dependent effects of folic acid on blood concentrations of homocysteine: a meta-analysis of the randomized trials. Am J Clin Nutr 82, 806-812.

17. McNulty H, Dowey LRC, Strain JJ et al. (2006) Riboflavin lowers homocysteine in individuals homozygous for the MTHFR $677 \mathrm{C} \rightarrow \mathrm{T}$ polymorphism. Circulation 113, 74-80.

18. Hustad S, Ueland P, Vollset S et al. (2000) Riboflavin as a determinant of plasma total homocysteine: effect modification by the methylenetetrahydrofolate reductase C677T polymorphism. Clin Chem 46, 1065-1071.

19. McNulty H, McKinley MC, Wilson B et al. (2002) Impaired functioning of thermolabile methylenetetrahydrofolate reductase is dependent on riboflavin status: implications for riboflavin requirements. Am J Clin Nutr 76, 436-441.

20. Lewis SJ, Ebrahim S \& Smith GD (2005) Meta-analysis of MTHFR $677 \mathrm{C} \rightarrow \mathrm{T}$ polymorphism and coronary heart disease: does totality of evidence support causal role for homocysteine and preventive potential of folate? $\mathrm{Br} \mathrm{Med}$ $J$ 331, 1053-1056.

21. Wald DS, Law M \& Morris JK (2002) Homocysteine and cardiovascular disease: evidence on causality from a meta-analysis. $\mathrm{Br}$ Med $J$ 325, 1202.

22. Casas JP, Bautista LE, Smeeth L et al. (2005) Homocysteine and stroke: evidence on a causal link from Mendelian randomisation. Lancet 365, 224-232.

23. Wald DS, Morris JK \& Wald NJ (2011) Reconciling the evidence on serum homocysteine and ischaemic heart disease: a meta-analysis. Plos ONE 6, e16473.

24. Clarke R, Bennett DA, Parish S et al. (2012) Homocysteine and coronary heart disease: meta-analysis of MTHFR case-control studies, avoiding publication bias. Plos Med 9, e1001177.

25. Kauwell GPA, Diaz ML, Yang Q et al. (2009) Folate: recommended intakes, consumption, and status. In Folate in Health and Disease, 2nd ed., pp. 467-490 [LB Bailey, editor]. Boca Raton, FL: Taylor \& Francis.

26. Yang Q, Bailey L, Clarke R et al. (2012) Prospective study of methylenetetrahydrofolate reductase (MTHFR) variant C677T and risk of all-cause and cardiovascular disease mortality among 6000 US adults. Am J Clin Nutr 95, 1245-1253.

27. Wang WY, Lee ET, Fabsitz RR et al. (2006) A longitudinal study of hypertension risk factors and their relation to cardiovascular disease - The Strong Heart Study. Hypertension 47, 403-409.

28. Lewington S, Clarke R, Qizilbash N et al. (2002) Prospective Studies Collaboration. Age-specific relevance of usual blood pressure to vascular mortality: a meta-analysis of individual data for one million adults in 61 prospective studies. Lancet 360, 1903-1913.

29. Mongeau JG (1987) Heredity and blood-pressure in humans - an overview. Pediatr Nephrol 1, 69-75.

30. Levy D, DeStefano AL, Larson MG et al. (2000) Evidence for a gene influencing blood pressure on chromosome 17 - genome scan linkage results for longitudinal blood pressure phenotypes in subjects from the Framingham Heart Study. Hypertension 36, 477-483.

31. Ehret GB, Munroe PB, Rice KM et al. (2011) Genetic variants in novel pathways influence blood pressure and cardiovascular disease risk. Nature 478, 103-109.

32. Liu C, Li H, Qi Q et al. (2011) Common variants in or near FGF5, CYP17A1 and MTHFR genes are associated with blood pressure and hypertension in Chinese Hans. J Hypertens 29, 70-75.

33. Tomaszewski M, Debiec R, Braund PS et al. (2010) Genetic architecture of ambulatory blood pressure in the general population insights from cardiovascular genecentric array. Hypertension 56, 1069-U146.

34. Takeuchi F, Isono M, Katsuya T et al. (2010) Blood pressure and hypertension are associated with 7 Loci in the Japanese population. Circulation 121, 2302-U140.

35. Heux S, Morin F, Lea RA et al. (2004) The methylentetrahydrofolate reductase gene variant (C677T) as a risk factor for essential hypertension in Caucasians. Hypertens Res 27, 663-667.

36. Poduri A, Kumari S, Jain S et al. (2009) A case-control study of the association between the MTHFR gene and essential hypertension in Asian Indians. $J$ Hum Hypertens 23, 140-142.

37. Inamoto $\mathrm{N}$, Katsuya $\mathrm{T}$, Kokubo $\mathrm{Y}$ et al. (2003) Association of methylenetetrahydrofolate reductase gene polymorphism with carotid atherosclerosis depending on smoking status in a Japanese general population. Stroke 34, 1628-1633.

38. Qian X, Lu Z, Tan M et al. (2007) A meta-analysis of association between C677T polymorphism in the methylenetetrahydrofolate reductase gene and hypertension. Eur $J$ Hum Genet 15, 1239-1245.

39. Koubaa N, Nakbi A, Smaoui A et al. (2007) Hyperhomocysteinemia and elevated ox-LDL in Tunisian type 2 diabetic patients: role of genetic and dietary factors. Clin Biochem 40, 1007-1014.

40. Benes P, Kankova K, Muzik J et al. (2001) Methylenetetrahydrofolate reductase polymorphism, type II diabetes mellitus, coronary artery disease, and essential hypertension in the Czech population. Mol Genet Metab 73, 188-195.

41. Koupepidou P, Deltas C, Christofides TC et al. (2005) The MTHFR 677TT and 677CT/1298AC genotypes in Cypriot patients may be predisposing to hypertensive nephrosclerosis and chronic renal failure. Int Angiol 24, 287-294

42. Jiang SQ, Hsu YH, Xu X et al. (2004) The C677T polymorphism of the methylenetetrahydrofolate reductase gene is associated with the level of decrease on diastolic blood pressure in essential hypertension patients treated by angiotensin-converting enzyme inhibitor. Thromb Res 113, 361-369.

43. Jiang S, Yu Y, Venners SA et al. (2011) Effects of MTHFR and MS gene polymorphisms on baseline blood pressure and Benazepril effectiveness in Chinese hypertensive patients. J Hum Hypertens 25, 172-177.

44. Xu H, Zheng H, Shen Y et al. (2012) Polymorphism of the methylenetetrahydrofolate reductase gene C677T and its 
influence on the antihypertensive and vascular protective effects of short-term lercanidipine treatment. Gene $\mathbf{5 0 0}$, 207-210.

45. Williams C, Kingwell BA, Burke K et al. (2005) Folic acid supplementation for $3 \mathrm{wk}$ reduces pulse pressure and large artery stiffness independent of MTHFR genotype. Am J Clin Nutr 82, 26-31.

46. Markan S, Sachdeva M, Sehrawat BS et al. (2007) MTHFR 677 CT/MTHFR 1298 CC genotypes are associated with increased risk of hypertension in Indians. $\mathrm{Mol}$ Cell Biochem 302, 125-131.

47. Wilson CP, McNulty H, Scott JM et al. (2010) The MTHFR C677T polymorphism, B-vitamins and blood pressure. Proc Nutr Soc 69, 156-165.

48. McNulty H, Strain JJ, Pentieva K et al. (2012) Vitamins, infectious and chronic disease during adulthood and aging C1metabolism and CVD outcomes in older adults. Proc Nutr Soc 71, 213-221.

49. Horigan G, McNulty H, Ward M et al. (2010) Riboflavin lowers blood pressure in cardiovascular disease patients homozygous for the $677 \mathrm{C} \rightarrow \mathrm{T}$ polymorphism in MTHFR. J Hypertens 28, 478-486.

50. Wilson CP, Ward M, McNulty H et al. (2012) Riboflavin offers a targeted strategy for managing hypertension in patients with the MTHFR 677TT genotype: a 4-y follow-up. Am J Clin Nutr 95, 766-772.

51. Wilson CP, McNulty H, Ward M et al. (2013) Blood pressure in treated hypertensive individuals with the MTHFR 677TT genotype is responsive to intervention with riboflavin: findings of a targeted randomized trial. Hypertension 61, 1302-1308.

52. Antoniades C, Shirodaria C, Leeson P et al. (2009) MTHFR $677 \mathrm{C} \rightarrow \mathrm{T}$ polymorphism reveals functional importance for 5-methyltetrahydrofolate, not homocysteine, in regulation of vascular redox state and endothelial function in human atherosclerosis. Circulation 119, 25072515.

53. Daly L, Kirke P, Molloy A et al. (1995) Folate levels and neural-tube defects - implications for prevention. JAMA 274, 1698-1702.

54. Daly S, Mills JL, Molloy AM et al. (1997) Minimum effective dose of folic acid for food fortification to prevent neural-tube defects. Lancet 350, 1666-1669.

55. Pitkin RM (2007) Folate and neural tube defects. Am J Clin Nutr 85, 285S-288S.

56. Nilsen RM, Vollset SE, Gjessing HK et al. (2006) Patterns and predictors of folic acid supplement use among pregnant women: the Norwegian Mother and Child Cohort Study. Am J Clin Nutr 84, 1134-1141.

57. McNulty B, Pentieva K, Marshall B et al. (2011) Women's compliance with current folic acid recommendations and achievement of optimal vitamin status for preventing neural tube defects. Hum Reprod 26, 15301536.

58. Botto LD, Lisi A, Robert-Gnansia E et al. (2005) International retrospective cohort study of neural tube defects in relation to folic acid recommendations: are the recommendations working? $\mathrm{Br} \mathrm{Med} J$ 330, 571-573.

59. Centers for Disease Control and Prevention (2000) Folate Status in Women of Childbearing Age - United States, 1999. MMWR. Morbidity and Mortality Weekly Report 49: 962-5. http://www.cdc.gov/mmwr/preview/ mmwrhtml/mm4942a4.htm

60. Honein MA, Paulozzi LJ, Mathews TJ et al. (2001) Impact of folic acid fortification of the US food supply on the occurrence of neural tube defects. JAMA $\mathbf{2 8 5}$, 2981-2986.
61. De Wals P, Tairou F, Van Allen MI et al. (2007) Reduction in neural-tube defects after folic acid fortification in Canada. $N$ Engl J Med 357, 135-142.

62. Blencowe H, Cousens S, Modell B et al. (2010) Folic acid to reduce neonatal mortality from neural tube disorders. Int J Epidemiol 39, 110-121.

63. Friso S \& Choi SW (2002) Gene-nutrient interactions and DNA methylation. J Nutr 132, 2382S-2387S.

64. Castro R, Rivera I, Ravasco P et al. (2004) 5,10-methylenetetrahydrofolate reductase (MTHFR) $677 \mathrm{C} \rightarrow \mathrm{T}$ and $1298 \mathrm{~A} \rightarrow \mathrm{C}$ mutations are associated with DNA hypomethylation. $J$ Med Genet 41, 454-458.

65. van der Put NMJ, Steegers Theunissen RPM, Frosst P et al. (1995) Mutated methylenetetrahydrofolate reductase as a risk factor for spina-bifida. Lancet 346, 1070-1071.

66. Blom HJ, Shaw GM, den Heijer M et al. (2006) Neural tube defects and folate: case far from closed. Nat Rev Neurosci 7, 724-731.

67. Ou CY, Stevenson R, Brown VK et al. (1995) C677T Homozygosity associated with thermolabile 5, 10 methylenetetrahydrofolate reductase as a risk factor for neural tube defects. Am J Hum Genet 57, A223-A223.

68. van der Put NMJ, van den Heuvel LP, Steegers Theunissen RPM et al. (1996) Decreased methylene tetrahydrofolate reductase activity due to the $677 \mathrm{C} \rightarrow \mathrm{T}$ mutation in families with spina bifida offspring. $J \mathrm{Mol}$ Med 74, 691-694.

69. van der Put NMJ, Eskes TKAB \& Blom HJ (1997) Is the common $677 \mathrm{C} \rightarrow \mathrm{T}$ mutation in the methylenetetrahydrofolate reductase gene a risk factor for neural tube defects? A meta-analysis. QJM Mon J Assoc Physicians 90, 111115.

70. Whitehead A, Gallagher P, Mills J et al. (1995) A geneticdefect in 5,10-methylenetetrahydrofolate reductase in neural-tube defects. QJM Mon J Assoc Physicians 88, 763-766.

71. van der Put NMJ, Trijbels FJM, Hol F et al. (1996) Mutated methylenetetrahydrofolate reductase in sporadic and hereditary spina bifida offspring. In Proceedings of III workshop on methionine metabolism, molecular mechanism and clinical implications, pp. 186-191 [JM Mato and A Caballero, editors]. Madrid: Consejo Superior de Investigaciones Cientificas.

72. Shields DC, Kirke PN, Mills JL et al. (1999) The "thermolabile" variant of methylenetetrahydrofolate reductase and neural tube defects: an evaluation of genetic risk and the relative importance of the genotypes of the embryo and the mother. Am J Hum Genet 64, 10451055.

73. Shaw GM, Rozen R, Finnell RH et al. (1998) Maternal vitamin use, genetic variation of infant methylenetetrahydrofolate reductase, and risk for spina bifida. $A m J$ Epidemiol 148, 30-37.

74. Martinez de Villarreal LE, Delgado-Enciso I, ValdezLeal R et al. (2001) Folate levels and N(5),N (10)-methylenetetrahydrofolate reductase genotype (MTHFR) in mothers of offspring with neural tube defects: a case-control study. Arch Med Res 32, 277-282.

75. Volcik KA, Blanton SH, Tyerman GH et al. (2000) Methylenetetrahydrofolate reductase and spina bifida: evaluation of level of defect and maternal genotypic risk in Hispanics. Am J Med Genet 95, 21-27.

76. Christensen B, Arbour L, Tran P et al. (1999) Genetic polymorphisms in methylenetetrahydrofolate reductase and methionine synthase, folate levels in red blood cells, and risk of neural tube defects. Am J Med Genet 84, $151-157$. 
77. Reilly R, Ward M, McNulty H et al. (2012) MTHFR 677 TT genotype and folate requirements for preventing neural tube defects: is there a case for personalised nutrition? Proc Nutr Soc 71, E29.

78. Crider KS, Zhu J, Hao L et al. (2011) MTHFR $677 \mathrm{C} \rightarrow \mathrm{T}$ genotype is associated with folate and homocysteine concentrations in a large, population-based, double-blind trial of folic acid supplementation. Am J Clin Nutr 93, 13651372.

79. Also-Rallo E, Lopez-Quesada E, Urreizti R et al. (2005) Polymorphisms of genes involved in homocysteine metabolism in preeclampsia and in uncomplicated pregnancies. Eur J Obstet Gynecol Reprod Biol 120, 45-52.

80. Saudan P, Brown MA, Buddle ML et al. (1998) Does gestational hypertension become pre-eclampsia? $\mathrm{Br} J$ Obstet Gynaecol 105, 1177-1184.

81. Hibbard BM (1964) The role of folic acid in pregnancy; with particular reference to anaemia, abruption and abortion. J Obstet Gynaecol Br Commonw 71, 529-542.

82. Hibbard BM, Hibbard ED \& Jeffcoate TN (1965) Folic acid and reproduction. Acta Obstet Gynecol Scand 44, $375-400$.

83. Stone ML, Luhby AL, Feldman R et al. (1967) Folic acid metabolism in pregnancy. Obstet Gynecol 99, 638-648.

84. Stone ML (1968) Effects on the fetus of folic acid deficiency in pregnancy. Clin Obstet Gynecol 11, 11431153.

85. Ray JG \& Mamdani MM (2002) Association between folic acid food fortification and hypertension or preeclampsia in pregnancy. Arch Intern Med 162, 1776-1777.

86. Hernandez-Diaz S, Wu XF, Hayes C et al. (2005) Methylenetetrahydrofolate reductase polymorphisms and the risk of gestational hypertension. Epidemiology 16, 628-634.

87. Sohda S, Arinami T, Hamada H et al. (1997) Methylenetetrahydrofolate reductase polymorphism and pre-eclampsia. J Med Genet 34, 525-526.

88. Grandone E, Margaglione M, Colaizzo D et al. (1997) Factor V Leiden, C $\rightarrow$ T MTHFR polymorphism and genetic susceptibility to preeclampsia. Thromb Haemost 77, $1052-1054$.

89. Wilcken B, Bamforth F, Li Z et al. (2003) Geographical and ethnic variation of the $677 \mathrm{C} \rightarrow \mathrm{T}$ allele of 5,10 methylenetetrahydrofolate reductase (MTHFR): findings from over 7000 newborns from 16 areas worldwide. $\mathrm{J} \mathrm{Med}$ Genet 40, 619-625.

90. Villar J, Say L, Shennan A et al. (2004) Methodological and technical issues related to the diagnosis, screening, prevention, and treatment of pre-eclampsia and eclampsia. Int J Gynaecol Obstet 85, S28-S41.

91. Perez-Mutul J, Gonzalez-Herrera L, Sosa-Cabrera T et al. (2004) A mutation in the 5,10-methylenetetrahydrofolate reductase gene is not associated with preeclampsia in women of southeast Mexico. Arch Med Res 35, 231234.

92. Davalos IP, Moran MC, Martinez-Abundis E et al. (2005) Methylenetetrahydrofolate reductase C677T polymorphism and factor $\mathrm{V}$ Leiden variant in Mexican women with preeclampsia/eclampsia. Blood Cells Mol Dis 35, 66-69.
93. Canto MJ, Buixeda M, Palau J et al. (2007) Early ultrasonographic diagnosis of diastrophic dysplasia at 12 weeks of gestation in a fetus without previous family history. Prenat Diagn 27, 976-978.

94. Kosmas IP, Tatsioni A \& Ioannidis JPA (2004) Association of C677T polymorphism in the methylenetetrahydrofolate reductase gene with hypertension in pregnancy and pre-eclampsia: a meta-analysis. $J$ Hypertens 22, 1655-1662.

95. Xia X, Chang W \& Cao Y (2012) Meta-analysis of the methylenetetrahydrofolate reductase C677T polymorphism and susceptibility to pre-eclampsia. Hypertens Res 35, 1129-1134.

96. Kupferminc MJ (2005) Thrombophilia and pregnancy. Curr Pharm Des 11, 733-746.

97. Powers RW, Minich LA, Lykins DL et al. (1999) Methylenetetrahydrofolate reductase polymorphism, folate, and susceptibility to preeclampsia. J Soc Gynecol Invest 6, 74-79.

98. Kobashi G, Yamada H, Asano T et al. (2000) Absence of association between a common mutation in the methylenetetrahydrofolate reductase gene and preeclampsia in Japanese women. Am J Med Genet 93, 122-125.

99. Laivuori H, Kaaja R, Ylikorkala O et al. (2000) 677 $\mathrm{C} \rightarrow \mathrm{T}$ polymorphism of the methylenetetrahydrofolate reductase gene and preeclampsia. Obstet Gynecol 96, 277-280.

100. Rigo J, Nagy B, Fintor L et al. (2000) Maternal and neonatal outcome of preeclamptic pregnancies: the potential roles of Factor V Leiden mutation and 5,10 methylenetetrahydrofolate reductase. Hypertens Pregnancy 19, 163 172 .

101. Morrison ER, Miedzybrodzka ZH, Campbell DM et al. (2002) Prothrombotic genotypes are not associated with pre-eclampsia and gestational hypertension: results from a large population-based study and systematic review. Thromb Haemost 87, 779-785.

102. Prasmusinto D, Skrablin S, Hofstaetter C et al. (2002) The methylenetetrahydrofolate reductase $677 \mathrm{C} \rightarrow \mathrm{T}$ polymorphism and preeclampsia in two populations. Obstet Gynecol 99, 1085-1092.

103. Pegoraro RJ, Chikosi A, Rom L et al. (2004) Methylenetetrahydrofolate reductase gene polymorphisms in black South Africans and the association with preeclampsia. Acta Obstet Gynecol Scand 83, 449-454.

104. Williams MA, Sanchez SE, Zhang C et al. (2004) Methylenetetrahydrofolate reductase $677 \mathrm{C} \rightarrow \mathrm{T}$ polymorphism and plasma folate in relation to pre-eclampsia risk among Peruvian women. J Matern Fetal Neonatal Med 15, 337-44.

105. Yilmaz H, Unlucerci Y, Gurdol F et al. (2004) Association of pre-eclampsia with hyperhomocysteinaemia and methylenetetrahydrofolate reductase gene C677T polymorphism in a Turkish population. Aust $N$ Z J Obstet Gynaecol 44, 423-427.

106. Stiefel P, Luisa Miranda M, Bellido LM et al. (2009) Genotype of the CYBA promoter-930A/G, polymorphism C677T of the MTHFR and APOE genotype in patients with hypertensive disorders of pregnancy: an observational study. Med Clin 133, 657-661. 